\title{
Case Report on Tuberculous Endometritis
}

\author{
Amita Singla* \\ Department of Obstetrics \& Gynaecology, Ashford Hospital, Australia
}

Submission: August 01, 2018; Published: September 25, 2018

*Corresponding author: Amita Singla, Department of Obstetrics \& Gynaecology, Ashford Hospital, Australia, Email: Amita.Singla@sa.gov.au

Keywords: Tuberculosis endometritis; Pathological diagnosis; Clinical evidence; Infection; Fallopian tubes; Infertility; Menstrual irregularity; Polycystic ovarian disease; Caesarean delivery; Contraception; Endometrial cavity; Epitheliod histiocytes; Lymphocytes; Plasma cells; Granulomatosis; Rifampicin; X-rays; Female genital tuberculosis; Malignancy; Oral contraceptive pills; Hysteroscopy; Transvaginal; HIV;

Abdominal distinction

\section{Introduction}

Tuberculosis Endometritis was described in 1847 by Morgani but it has remained mainly as pathological diagnosis and has been always over shadowed by pelvic Tuberculosis. Recently Tuberculosis has been reported in the Endometrium of the patients who otherwise have no other clinical evidence of infection in the fallopian tubes or elsewhere.

Patients usually are not obviously ill but could complain of infertility or menstrual irregularity.

\section{Case Report}

We report such a case of a well woman who presented with menstrual irregularity. Mrs. Al was at the time of presentation a 37 year old woman who presented with the history of irregular heavy periods in the setting of Polycystic Ovarian Disease. She had not been using any contraception. She had had one caesarean delivery of twins; however, she needed IVF for conception. She had been otherwise well and had no major issues [1].

On discussion and after confirming presence of Polycystic Ovarian Disease, she was offered insertion of Mirena after sampling of the endometrial cavity. At the time of Hysteroscopy, granular Endometritis was noted and was sent for histology. Histology indicated presence of epitheliod histiocytes with frequent giant cells with langherns type. There was presence of necrosis with cell debrisin polymorphs withcasseous quality. Endometrium also contained lymphocytes and plasma cells. Acid fast stain confirmed presence of granulomatosis Endometritis with necrosis and Tuberculosis. Her pap smear done at the same time was negative for any cervical lesion [2].

The patient was referred to infectious disease for further management. She was started on anti-tubercular regimen with INH Rifampicin ethambutol prizinamide for 6 months. For 4 drugs and for 2 months and then a further 4 months of INH and rifampicin she had screening $\mathrm{x}$-rays prior to migrating to Australia which was within normal limits and had had mountex test which was within normal limits. At the end of 6 months, she had a repeat Hysteroscopy D \& C which indicated resolution of previously noted granulomatosis Endometritis and histology had confirmed presence of no acid fast bacilli.

Tuberculosis Endometritis was first described by Morgani in 18th Century after Tuberculosis was discovered by Cochs. Tuberculosis of genital track is almost invariably secondary to disease elsewhere usually in lung. $13 \%$ of patients with primary Tuberculosis develop genital infections. Female genital Tuberculosis is a rare disease in developed countries but is a frequent cause of chronic pelvic inflammatory disease and infertility in that parts of world [3].

A 37 year old gravida 2 para $1+1$ woman presented with history of irregular heavy periods for past 6 months with large clots. There was no pain in the abdomen and no intermenstrual or post coital bleeding. The patient was otherwise well and had no significant medical history. She had no personal or family history of Gynaecological or any other infectious diseases of malignancy. She was not smoking or had alcohol or substance abuse. She had not used oral contraceptive pills.

She had one successful conception and one miscarriage after IVF following infertility. Her investigations at that time of infertility including Hysteroscopy, Laparoscopy and U/S had been all within normal limits.

On examination she was noted to be a healthy woman. Transvaginal U/S was within normal limits. She was taken for Hysteroscopy and insertion of Mirena. A large amount of curettings were obtained which were granular in appearance and a granulomatous Endometritis was noted at the time of Hysteroscopy. Patient was discharged home the same day and the histology showed Langhans giant cells [4]. 
Patients Hepatitis and HIV status was negative. All the hematological and biological examinations were normal. Diagnosis of Tuberculosis Endometritis was confirmed. Other tests for Tuberculosis Monteux were also negative. Chest x-ray showed no abnormality. The patient received anti-tuberculosis treatment for drugs for 6 months. At subsequent follow up visit. Patient has been doing well and has been disease free for last 4 years.

\section{Discussion}

Genital Tuberculosis is usually caused by reactivation of organism from systemic distribution during primary infection. It is estimated about 8 million cases of Tuberculosis worldwide every year and $95 \%$ are carrying developing world. Tuberculosis usually affects the Lung but about $1 / 3$ patients have extra pulmonary spread.

Extra pulmonary Tuberculosis is shown in a greater proportion of new cases in developed world and this trend is increasing. The research in Tuberculosis in the developed world may be explained by the increase of immigrants from areas where the disease is endemic as well as with increasing prevalence of HIV infections with Tuberculosis being one of the opportunistic infection in the individual infected with this virus. People with latent Tuberculosis infections are at a higher risk of progression to active disease if co-infected with HIV.

Genital Tuberculosis is an indolent infection. It may not manifest after initial seeding. The most common presentation reported is infertility, pelvic pain, vaginal bleeding, amenorrhea and vaginal discharge. Less common presentation is abdominal mass, ascites ischio-rectal abscess and weight abdominal distinction.

There are very few data on optical medical management of genital Tuberculosis. Treatment guide recommends 6 months of treatment providing pyrazinamide is included for first 2 months and of the treatment and the organism is susceptible. Surgical treatment is usually of total abdominal Hysterectomy and
Bilateral Salpino-Oophorectomy. Indications for surgery would be persistent of pelvic mass, oracles of pain or bleeding after 9 months of treatment. Surgery should be performed at least 6 weeks after initiation of anti-tuberculosis medication and thus reduce the risk of post operative complication.

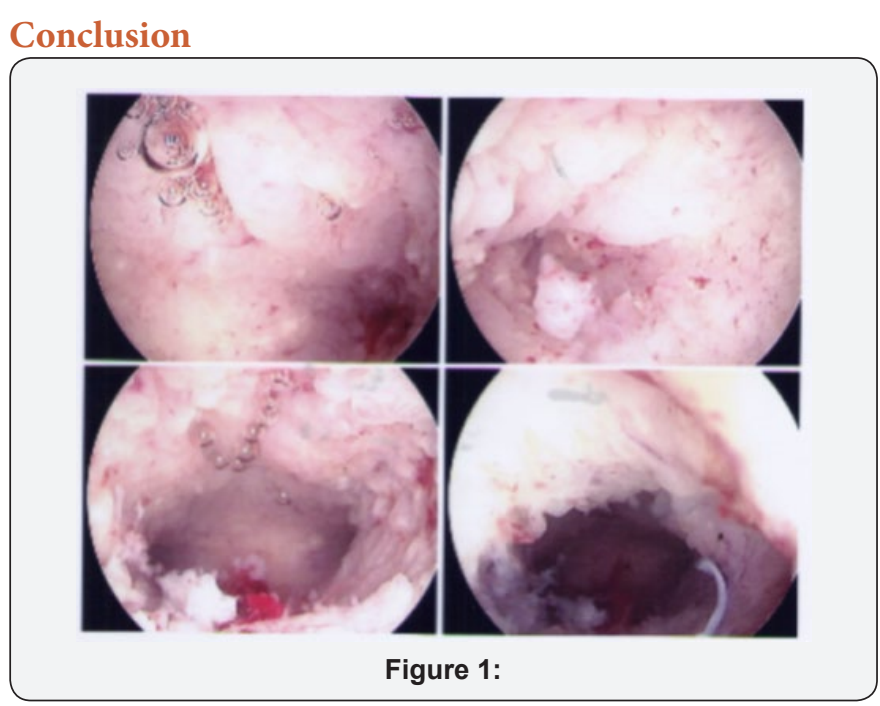

Genital Tuberculosis is not a common condition in women in developing world. We recommend that all patients with a positive Monteux result and menstrual abnormalities undergo aggressive evaluation for Genital Tuberculosis (Figure 1).

\section{References}

1. Bobrew ML, Batts JA (1952) Pelvictubercu-losis. Am J Obst \& Gynec 64: 1242.

2. Mass Gen Hosp Case38282, J Med (1948) Tuberculosis Sal-pingitisand Endometritis, New England 239: 67.

3. Novak Emil (1940) Gynecological and Obstetrical Pathology. Philadelphia, WB Saunders Company, Scotland, UK 223-225.

4. Tuberculous endometritis: Its association with infertility and other gynaecological complaints in Indian women.

Your next submission with Juniper Publishers
will reach you the below assets
- Quality Editorial service
- Swift Peer Review
- Reprints availability
- E-prints Service
- Manuscript Podcast for convenient understanding
- Global attainment for your research
- Manuscript accessibility in different formats
( Pdf, E-pub, Full Text, Audio)
- Unceasing customer service
Track the below URL for one-step submission
https://juniperpublishers.com/online-submission.php

